DOI: https://doi.org/10.24127/ajpm.v10i4.4334

\title{
PENGARUH MODEL REALISTIC MATHEMATICS EDUCATION TERHADAP KEMAMPUAN LITERASI MATEMATIKA DITINJAU DARI SELF EFFICACY SISWA
}

\author{
Prastika Istiqomah $^{1}$, Kamid ${ }^{2}$, Muhammad Haris Effendi-Hasibuan ${ }^{3 *}$ \\ ${ }^{1,2}$ Program Magister Pendidikan Matematika Universitas Jambi , Jambi, Indonesia \\ ${ }^{3 *}$ Program Magister Pendidikan Kimia Universitas Jambi, Jambi, Indonesia \\ *Jambi, 36361, Jambi, Indonesia. \\ E-mail: $\quad$ prastikaisti91@gmail.com $^{1)}$ \\ kamid.fkip@unja.ac.id ${ }^{2}$ \\ hariseffendi@unja.ac.id $^{3 *}$
}

Received 17 October 2021; Received in revised form 02 December 2021; Accepted 27 December 2021

\begin{abstract}
Abstrak
Penelitian ini menerapkan model pembelajaran berbasis realistic mathematics education yang dapat menjadi solusi bagi guru dalam mengoptimalkan kemampuan literasi matematika siswa. Penelitian ini bertujuan untuk mengetahui pengaruh penerapan model pembelajaran realistic mathematics education (RME) terhadap kemampuan literasi matematika siswa, pengaruh self-efficacy terhadap kemampuan literasi matematika siswa, dan melihat interaksi model RME dan self-efficacy terhadap kemampuan literasi matematika. Penelitian ini merupakan penelitian eksperimen yang menggunakan posttest only control design. Populasi penelitian ini adalah seluruh siswa kelas VIII SMP Negeri 9 Kota Jambi tahun ajaran 2021/2022 sebanyak 228 siswa dan terbagi menjadi 7 kelas. Dalam penelitian ini, sampel yang digunakan adalah sebanyak 68 siswa yang terbagi menjadi dua kelas (kelas eksperimen I dan kelas kontrol). Sampel di tentukan dengan teknik Simple Random Sampling. Instrumen yang digunakan dalam penelitian ini ialah angket self-efficacy dan tes kemampuan literasi matematika. Data yang diperoleh dianalisis menggunakan uji ANOVA dua jalur. Hasil penelitian ini yaitu Model pembelajaran RME lebih efektif mempengaruhi kemampuan literasi matematika dibandingkan dengan pembelajaran konvensional, serta self-efficacy dengan kategori tinggi dan sedang lebih mempengaruhi kemampuan literasi matematika dibandingkan self-efficacy siswa dengan kategori rendah.
\end{abstract}

Kata kunci: Kemampuan literasi matematika; realistic mathematics education; self-efficacy.

\begin{abstract}
This study aims to determine the effect of applying the realistic mathematics education (RME) learning model on students' mathematical literacy skills, the effect of self-efficacy on students' mathematical literacy skills and see the interaction of the RME models and self efficacy on mathematical literacy skills. This research is an experimental study using a posttest only control design. The population of this study was all students of class VIII SMP Negeri 9 Jambi City for the academic year 2021/2022 as many as 228 students and divided into 7 classes. In this study, the sample used was 68 students who were divided into two classes (experimental class I and control class). The sample is determined by the Simple Random Sampling technique. The instruments used in this study were self-efficacy questionnaires and tests of mathematical literacy skills. The data obtained were analyzed using a two-way ANOVA test. The results of this study are that the RME learning model is more effective in influencing mathematical literacy skills compared to conventional learning, and self-efficacy with high and medium categories affects mathematical literacy skills more than students' self-efficacy in low categories.
\end{abstract}

Keywords: Literacy mathematics; realistic mathematics education; self-efficacy.

This is an open access article under the Creative Commons Attribution 4.0 International License 
DOI: https://doi.org/10.24127/ajpm.v10i4.4334

\section{PENDAHULUAN}

Matematika merupakan salah satu bidang studi yang memiliki peran penting dalam pemikiran abad ke-21. Matematika lebih menekankan pada proses berpikir dalam urutan beberapa langkah logis dan sistematis untuk menyelesaikan suatu masalah tertentu. Matematika bukanlah soal memasukkan angka ke dalam rumus dan melakukan perhitungan hafalan, tetapi matematika lebih kepada cara berpikir dan mengeksplorasi hal-hal yang masih dianggap asing bagi siswa (Dewanti et al., 2020)

Beberapa penelitian yang berkaitan dengan kemampuan literasi matematika mengatakan bahwa dengan kemampuan literasi matematika, manusia dapat memecahkan masalah yang berkaitan dengan berbagai konteks dalam kehidupan secara matematis sesuai dengan prinsip matematika (Hayati \& Kamid, 2019). Literasi matematika memainkan peran penting sebagai salah satu keterampilan hidup. Ini adalah keterampilan dasar yang sama pentingnya dengan literasi. Oleh karena itu, pengajaran matematika di sekolah harus bertujuan untuk mengembangkan literasi matematika dan meningkatkan kemampuan setiap siswa untuk menggunakan dan menerapkan pengetahuan matematika untuk memecahkan masalah atau situasi kehidupan nyata (Sumirattana, 2017).

Salah satu alternatifnya adalah menerapkan model pembelajaran yang baik digunakan adalah Realistic Mathematics Education (RME). Pembelajaran RME memotivasi setiap siswa yang belajar matematika dalam kapasitas konteks matematika yang digunakan dalam pemecahan masalah matematika sehingga memudahkan penyelesaiannya (Wardono et al., 2016). Dalam proses pembelajaran matematika aktivitas siswa yang akan muncul dalam penggunaan model pembelajaran RME didorong oleh rasa kepercayaan diri terhadap kemampuannya sendiri dalam menyelesaikan masalah yg berkaitan dengan kehidupan sehari-hari agar tercapai tujuan yang diinginkan disebut self-efficacy. Hal ini sejalan dengan peneltian yang dilakukan (Ozgen, 2013) bahwa siswa dengan self-efficacy yang baik dalam menyelesaikan masalah konteks nyata dalam prosesnya dapat meningkatkan kemampuan literasi yang dimilikinya. Hal ini sejalan dengan pendapat (Dian et al., 2020) Perlu dimunculkan rasa percaya diri atau selfefficacy pada diri siswa saat belajar.

Namun dari beberapa penelitian tersebut, belum banyak penggunaan model realistic mathematics education dalam proses pembelajaran di sekolah untuk meningkatkan kemampuan literasi matematika siswa yang berdasarkan oleh self-efficacy, khususnya pada materi relasi dan fungsi. Padahal faktanya berdasarkan data observasi awal yang ditemukan di lapangan, masih banyak siswa yang kesulitan menyelesaikan soal kemampuan literasi matematika, baik itu siswa yang memiliki self-efficacy tinggi, sedang, ataupun siswa dengan selfefficacy yang rendah.

Oleh karena itu, berdasarkan uraian-uraian di atas, maka perlu diterapkan model pembelajaran yang mengangkat masalah kontekstual seperti realistic mathematics education dengan harapan agar kemampuan literasi matematika siswa dapat menjadi lebih baik dan siswa menjadi lebih mudah memahami konsep materi matematika yang diajarkan serta penggunaan model RME diharapkan dapat membuat selfefficacy lebih meningkat . 
DOI: https://doi.org/10.24127/ajpm.v10i4.4334

\section{METODE PENELITIAN}

Penelitian ini merupakan penelitian eksperimen. Tahapan penelitian ini dimulai dengan pada awal pembelajaran diberikan angket selfefficacy siswa, kemudian dalam proses pembelajaran diberikan perlakuan menggunakan model pembelajaran RME dengan total 4 kali pertemuan, pada akhir pertemuan siswa diberikan soal posttest kemampuan literasi matematika.

Populasi penelitian ini adalah seluruh kelas VII SMP Negeri 9 Kota jambi yang terdiri dari 228 siswa yang dibagi oleh 7 kelas. Penelitian ini dilakukan dengan teknik simple random sampling. Sampel terdiri dari 68 dimana terdapat 2 kelas yaitu kelas eksperimen (menggunakan pembelajaran berbasis RME) dan kelas kontrol (menggunakan model pembelajran konvensional).

Pada kelas eksperimen (VIII A) terdiri dari 34 siswa dan kelas kontrol (VIII C) dengan jumlah 34 siswa. Dalam penelitian ini terdiri dari tiga variabel yaitu variabel bebas, variabel terikat dan variabel moderator. Variabel bebas terdiri dari model pembelajaran, variabel terikat terdiri dari kemampuan literasi matematika dan variabel moderator adalah self-efficacy. Penelitian ini menggunakan posttest only control design. Selanjutnya rancangan penelitian dapat dilihat pada Tabel 2 .

Tabel 2. Rancangan Penelitian

\begin{tabular}{ccc}
\hline Kelas & Perlakuan & Post-test \\
\hline Eksperimen I & $X_{1}$ & $O_{2}$ \\
$(R M E)$ & & \\
Kontrol & $X_{2}$ & $O_{2}$ \\
(konvensional) & &
\end{tabular}

Keterangan:

$X_{1}$ : dengan model RME

$X_{2}$ : dengan model konvensional

Jenis instrumen yang digunakan dalam penelitian ini adalah tes dan angket. Angket yang digunakan ada indikator self-efficacy dengan jumlah pertanyaan ada 20 pertanyaan, angket ini menggunakan skala likert. Sedangkan instrument berupa tes yaitu tes kemampuan literasi matematika siswa yang terdiri dari 2 soal. Materi yang diberikan yaitu materi relasi dan fungsi dengan indikator yang telah ditentukan.

Teknik analisis data penelitian ini dilakukan dengan beberapa uji yang terdiri dari:

1. Uji Validitas Isi

Uji validitas isi terhadap instrument soal dan angket yang diuji oleh ahli yaitu dosen pasca sarjana UNJA.

\section{Uji Validitas Konstruk}

Untuk perhitungan validitas butir soal menggunakan rumus product moment. Hasilnya dari 2 butir soal tes kemampuan literasi matematika siswa yang telah diuji cobakan semua soal valid.

\section{Uji Reliabilitas}

Pada uji reliabilitas ini menggunakan rumus alpha. Hasilnya yaitu tes kemampuan literasi matematika siswa sebesar 0,72 dengan keterangan reliabilitas tinggi.

\section{Uji Daya Beda dan Tingkat Kesukaran Tes}

Hasilnya yaitu kedua soal memiliki daya beda Cukup dengan tingkat kesukarannya dalam katagori mudah, dan sedang.

Selanjutnya dilakukan uji prasyarat hipotesis, yaitu uji normalitas dan uji homogenitas, setelah uji prasyarat normalitas dan homogenitas terpenuhi maka dpaat dilakukan uji hipotesis dengan menggunakan Anova dua arah. 


\section{HASIL DAN PEMBAHASAN}

Data yang terkumpul dalam penelitian ini terdiri atas data selfefficacy dan data kemampuan literasi matematika siswa pada materi relasi dan fungsi. Data diperoleh dari kelas eksperimen I dengan menggunakan model RME, kelas kontrol dengan menggunakan model konvensional. Data self-efficacy ini diperoleh melalui angket tentang indikator dari self-efficacy, adapun hasil self-efficacy siswa dapat disajikan pada Gambar 1.

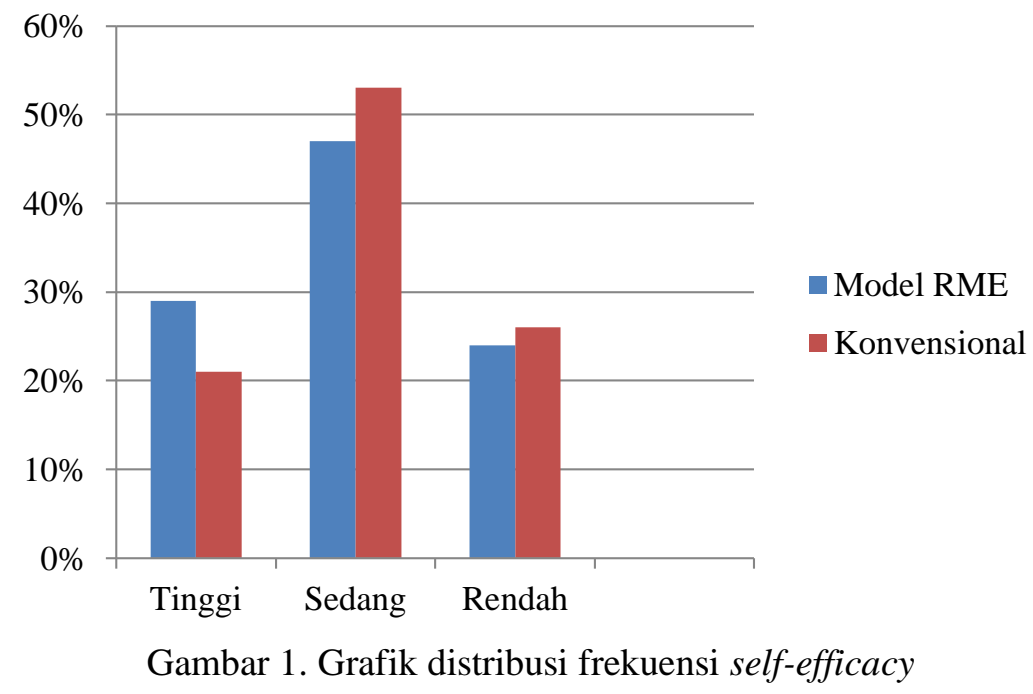

Data Kemampuan literasi matematika ini diperoleh melalui tes, tes ini dilakukan untuk mengukur kemampuan literasi matematika yang dimiliki siswa. Adapun hasilnya dapat disajikan dalam
Tabel 3. Sebelum melakukan uji anova dua arah, terlebih dahulu kita melakukan uji prasyarat dari soal berupa uji normalitas dan uji homogenitas. Uji normalitas dapat dilihat pada Tabel 4 .

Tabel 3. Data kemampuan literasi matematika

\begin{tabular}{lcccc}
\hline \multicolumn{1}{c}{ Model } & Data & Mean & Min & Maks \\
\hline Eksperimen & 34 & 13.35 & 7 & 19 \\
Kontrol & 34 & 9.85 & 5 & 14 \\
\hline
\end{tabular}

Tabel 4. Uji normalitas model pembelajaran

\begin{tabular}{ccccc}
\hline Model Pembelajaran & Statistik Hitung & df & $\boldsymbol{p}$-value & Keputasan \\
\hline RME & 0,96 & 34 & 0,34 & Normal \\
Konvensional & 0.95 & 34 & 0,17 & Normal \\
\hline
\end{tabular}

Berdasarkan hasil uji normalitas dari Shapiro Wilk dapat dilihat dari tabel 4, bahwa nilai signifikansi yang diperoleh dari kelas eksperimen dan control lebih besar dari 0,05 yaitu 0,34 untuk model RME, dan model konvensional sebesar 0,14 . Dengan demikian dapat diperoleh kesimpulan bahwa data tes kemampuan literasi matematika berdasarkan model pembelajaran berasal dari populasi yang berdistribusi normal.

Berdasarkan perhitungan uji homogenitas, hasil uji homogenitas dari 
DOI: https://doi.org/10.24127/ajpm.v10i4.4334

kelas eksperimen dan kelas kontrol yakni 0,22 lebih besar dari 0,05. Maka dapat disimpulkan bahwa sampel dalam penelitian berdasarkan model pembelajaran mempunyai varians yang sama.
Setelah uji prasyarat normalitas dan homogenitas terhadap soal terpenuhi, maka selanjutnya dapat dilakukan uji anova 2 arah. Hasil uji anova dapat dilihat pada Tabel 5.

Tabel 5. Uji two way Anova

\begin{tabular}{cccc}
\hline Model Pembelajaran & df & Mean & Sig. \\
\hline RME & 2 & 70.992 & 0.000 \\
Self-efficacy & 2 & 371.533 & 0.000 \\
Model Pembelajaran* & 4 & 1.965 & 0.240 \\
Self-efficacy & & & \\
\hline
\end{tabular}

Hasil uji anava dua arah pada hipotesis pertama menunjukan bahwa nilai signifikansi sebesar $0,000<0,05$. Adapun $H_{1}$ berbunyi terdapat pengaruh penerapan pembelajaran RME terhadap kemampuan literasi matematika siswa sedangkan $H_{0}$ berbunyi tidak terdapat pengaruh penerapan pembelajaran RME terhadap kemampuan literasi matematika siswa. Dengan demikian $H_{1}$ diterima dan $H_{0}$ ditolak. Jadi dapat disimpulkan bahwa Terdapat pengaruh model pembelajaran realistic mathematics education (RME), model pembelajaran konvensional terhadap kemampuan literasi matematika siswa. Model pembelajaran Realistic Mathematics Education (RME) memperoleh nilai mean sebesar 13.35 lebih tinggi dari model Konvensional yaitu sebesar 9,85. Sehingga dapat disimpulkan bahwa model pembelajaran Realistic Mathematics Education lebih efektif dibanding model pembelajaran konvensional dalam mempengaruhi kemampuan literasi matematika siswa.

Proses pemodelan dimulai dengan mengkonseptualisasikan beberapa situasi masalah. Dilanjutkan dengan penyederhanaan, penataan, dan pembuatan situasi yang lebih sesuai dengan pengetahuan, tujuan dan minat pemecahan masalah yang kemudian mengarah pada spesifikasi masalah. Langkah pertama dalam proses pemodelan adalah memahami situasi masalah yang diberikan untuk konstruksi selanjutnya (Hayati \& Kamid, 2019). Hal ini dilakukan oleh salah satu siswa pada kelas eksperimen I, siswa telah melakukan langkah-langkah menyelesaikan masalah dengan baik dan sesuai dengan ketiga indikator kemampuan literasi matematika menurut (OECD, 2013) yang dimulai dari memahami dan merumuskan masalah, terlihat siswa tersebut mampu mengetahui dan menuliskan apa saja yang diketahu dan ditanya pada soal dengan benar, menentukan perencanaan atau strategi berdasarkan keterangan diketahui dan ditanya pada soal yang dapat digunakan untuk menyelesaikan permasalahan yang diberikan, melaksanakan perencanaan dimana siswa dapat menyelesaikan masalah dengan rumus atau strategi yang telah ditentukan dan melakukan perhitungan dengan tepat, tidak lupa juga memperhatikan simbol dan gambar yang digunakan agar tidak keliru atau salah dalam penulisan tanda, simbol, ataupun gambar yang diperlukan dalam menyelesaikan masalah, setelah menemukan solusi yang tepat dari permasalahan, siswa mengecek kembali jawabannya agar dapat menyimpulkan 
jawaban yang berbentuk konteks matematika ke dalam bentuk konteks masalah dengan benar, yang juga berarti siswa tersebut meyakini jawaban yang ditulis adalah benar.

Berdasarkan uraian hasil penyelesaian posttest siswa dengan indikator kemampuan literasi matematika yang berkaitan dengan dunia nyata membuat siswa lebih mudah menyelesaikan masalah yang diberikan. Hal ini sejalan dengan pendapat (Hayati \& Kamid, 2019) bahwa literasi matematika juga membiasakan siswa dalam mengomunikasikan matematika dalam masalah di kehidupan mereka dan fenomena sehari-hari dan melatih siswa untuk dapat menjelaskan fenomena yang mereka hadapi dalam bahasa matematika yang singkat dan jelas.

Pembelajaran yang menerapkan Realistic Mathematics Education dapat meningkatkan kemampuan literasi matematika peserta didik seperti yang dikemukakan oleh (Sumirattana, 2017). Kemampuan literasi matematika siswa dapat dilihat dari bagaimana siswa menggunakan kemampuan dan keterampilan matematika untuk memecahkan masalah yang terjadi dalam berbagai situasi atau konteks yang berhubungan dengan setiap individu (Hayati \& Kamid, 2019). Dengan menggunakan Realistic Mathematics Education dalam pembelajaran dapat meningkatkan kemampuan literasi matematika yang dimiliki siswa. Hal ini juga sejalan dengan penelitian yang dilakukan oleh (Laurens et al., 2017; Yuanita, 2018) bahwa Realistic Mathematics Education lebih efektif dalam menemukan ide berfikir siswa karna berkaitan dengan konteks kehidupan nyata.

Tujuan utama dalam penggunaan realistic mathematics education dalam sebuah pembelajaran adalah agar memungkinkan siswa meningkatkan kemampuan mereka dalam menghadapi masalah dengan konteks dunia nyata dengan tepat (Heyden, 2016; Zaranis et al., 2013).

Hal ini sejalan dengan pendapat yang dikemukan oleh (Dickinson \& Hough, 2012) yang menyatakan bahwa menggunakan model pembelajaran Realistic mathematics education melibatkan siswa mengembangkan pemahaman mereka dengan terlibat melalui masalah dalam konteks yang melibatkan kemampuan siswa.

Hasil uji anava dua arah pada hipotesis kedua menunjukan menunjukan bahwa nilai signifikansi sebesar $0,000<0,05$. Adapun $H_{1}$ berbunyi terdapat pengaruh self-efficacy siswa terhadap kemampuan literasi matematika siswa sedangkan $H_{0}$ berbunyi tidak terdapat pengaruh selfefficacy terhadap kemampuan literasi matematika siswa. Dengan demikian $H_{1}$ diterima dan $H_{0}$ ditolak. Jadi dapat disimpulkan bahwa terdapat pengaruh self-efficacy tinggi, self-efficacy sedang, dan self-efficacy rendah terhadap kemampuan literasi matematika siswa. Karena $H_{0}$ ditolak maka dilanjutkan dengan uji lanjut, pada penelitian ini uji lanjut yang digunakan yakni uji tukey, hasil perhitungan uji tukey dapat dilihat pada Tabel 6 .

Tabel 6. Uji Tukey

\begin{tabular}{ccc}
\hline Self Efficacy & N & $\begin{array}{c}\text { Subset } \\
\mathbf{1}\end{array}$ \\
\hline Rendah & 24 & 7.42 \\
Sedang & 52 & 11.40 \\
Tinggi & 26 & 15.42 \\
\hline Sig & & $\mathbf{1 . 0 0 0}$ \\
\hline
\end{tabular}

Dari Tabel 6 dapat disimpulkan bahwa self-efficacy tinggi dan sedang lebih efektif dibandingkan siswa dengan self-efficacy yang rendah. 
DOI: https://doi.org/10.24127/ajpm.v10i4.4334

Berdasarkan hasil perhitungan pada penelitian ini, maka diperoleh bahwa kemampuan literasi matematika yang memiliki self-efficacy tinggi dan sedang lebih baik dibandingkan peserta didik yang memiliki self-efficacy rendah. Hal ini dikarenakan self-efficacy berpengaruh terhadap kemampuan literasi matematika siswa. Self-efficacy sebagai faktor utama keyakinan dalam diri seseorang akan kemampuan yang dimiliki dalam melakukan suatu tindakan dan menyelesaikan masalah untuk mencapai suatu tujuan yang telah ditetapkan, serta dapat mempengaruhi situasi dengan baik, dan dapat mengatasi sebuah hambatan yang akan ditemui saat menyelesaikan permasalahan.

Hal ini sejalan dengan teori dari Bandura bahwa Self-efficacy mengacu pada keyakinan peserta didik tentang kemampuan mereka untuk menyelesaikan tugas-tugas tertentu. Banyak penelitian yang menunjukkan bahwa self-efficacy mempengaruhi motivasi, ketekunan, upaya, tindakan, perilaku, dan prestasi manusia. Para peneliti telah menunjukkan bahwa self-efficacy yang lebih tinggi merupakan prediksi kinerja yang lebih tinggi. Jika ada hal negatif, seperti lelah, kurang sehat, cemas, atau tertekan, akan mengurangi tingkat SelfEfficacy seseorang. Sebaliknya, jika seseorang dalam kondisi prima, hal ini akan berkontribusi positif bagi perkembangan Self-Efficacy.

Lebih lanjut menurut (Ghofur et al., 2021) Peserta didik yang memiliki kemampuan literasi matematika yang baik jika memiliki ketekunan dan kepercayaan diri yang baik. Self efficacy termasuk salah satu faktor yang mempengaruhi dan mendukung kemampuan siswa dalam memahami konsep matematika.

Hal ini sejalan dengan penelitian sebelumnya yang dilakukan oleh
(Ozgen, 2013; Tariq et al., 2013) menunjukkan Pengaruh yang signifikan antara self efficacy dan kemampuan literasi matematika. Juga sejalan dengan penelitian yang dilakukan oleh (Indrawati \& Wardono, 2019) bahwa Self efficacy sangat berpengaruh terhadap kemampuan literasi matematika, baik itu self efficacy yang bersumber dari pengalaman keberhasilan diri sendiri, orang lain, atau bisa jadi karena kondisi fisiologis yang positif.

Hasil uji anava dua arah pada hipotesis ketiga menunjukan menunjukan bahwa nilai signifikansi sebesar $0,240>0,05$. Adapun $H_{1}$ berbunyi terdapat interaksi antara model pembelajaran RME dengan self-efficacy terhadap kemampuan literasi matematika siswa sedangkan $H_{0}$ berbunyi tidak terdapat interaksi antara model pembelajaran RME dengan self-efficacy terhadap kemampuan literasi matematika siswa. Dengan demikian $H_{0}$ diterima dan $H_{1}$ ditolak. Jadi dapat disimpulkan bahwa tidak terdapat interaksi antara model pembelajaran RME dengan selfefficacy terhadap kemampuan literasi matematika.

Model pembelajaran RME berpengaruh terhadap hasil kemampuan literasi matematika secara mandiri. Hal ini dikarenakan siswa diberikan perlakuan pembelajaran dengan sintaks model pembelajaran RME yang didasari oleh masalah kontekstual atau dunia nyata. Dengan model ini yang berbasis konteks dunia nyata mampu mengembangkan kemampuan matematika siswa untuk mendapat hasil belajar yang baik (Fahmy et al., 2018).

Self-efficacy siswa berpengaruh terhadap hasil kemampuan literasi matematika siswa secara mandiri. Hal ini dikarenakan self-efficacy adalah keyakinan siswa dalam melakukan suatu tindakan selama proses pembelajaran 
berlangsung. Dengan demikian, siswa dengan kategori self-efficacy tinggi dan sedang akan menghasilkan kemampuan literasi matematika yang lebih baik dibandingkan dengan self-efficacy siswa kategori rendah. Hasil penelitian ini diperkuat dengan temuan lain yang mengatakan bahwa kemampuan literasi matematika siswa dipengaruhi oleh selfefficacy yang dimiliki siswa (Ghofur et al., 2021).

Berdasarkan uraian-uraian tersebut, maka secara bersama-sama dapat dikatakan bahwa penggunaan pembelajaran berbasis (realistic mathematics education dan konvensional), serta selfefficacy tidak memiliki interaksi dalam mempengaruhi kemampuan literasi matematika siswa.

\section{KESIMPULAN DAN SARAN}

Berdasarkan hasil penelitian dan pembahasan dapat disimpulkan bahwa terdapat pengaruh model pembelajaran Realistic Mathematics Education (RME) terhadap kemampuan literasi matematika siswa, dan terdapat pengaruh self-efficacy terhadap kemampuan literasi matematika yang dimiliki tiap siswa. Model pembelajaran RME lebih efektif mempengaruhi kemampuan literasi matematika dibandingkan dengan pembelajaran konvensional, serta selfefficacy dengan kategori tinggi dan sedang lebih mempengaruhi kemampuan literasi matematika dibandingkan selfefficacy siswa dengan kategori rendah.

Berdasarkan penelitian diatas diharapkan peneliti lain bila menggunakan model pembelajaran realistic mathematics education (RME) hendaknya tidak menimbulkan salah konsep dalam proses pembelajarannya. Serta untuk memperhatikan self-efficacy sebaiknya melakukan tes tingkatan selfefficacy dan usaha yang diperlukan untuk meningkatkan self-efficacy siswa.

\section{DAFTAR PUSTAKA}

Dewanti, S. S., Kartowagiran, B., Jailani, J., \& Retnawati, H. (2020). Lecturers' Experience in Assessing 21St-Century Mathematics Competency in Indonesia. Problems of Education in the 21st Century, 78(4), 500-515. https://doi.org/10.33225/pec/20.78. 500

Dickinson, P., \& Hough, S. (2012). Using realistic mathematics education in UK classrooms. Centre for Mathematics Education, Manchester Metropolitan University, Manchester, UK.

Fahmy, A. F. R., Wardono, W., \& Masrukan, M. (2018). Kemampuan literasi matematika dan kemandirian belajar siswa pada model pembelajaran RME berbantuan Geogebra. PRISMA, Prosiding Seminar Nasional Matematika, 1, 559-567.

Ghofur, A., Masrukan, M., \& Rochmad, R. (2021). Mathematical literacy ability in experiential learning with performance assessment based on self-efficacy. Unnes Journal of Mathematics Education Research, 10(A).

Hayati, T. R., \& Kamid, K. (2019). Analysis of Mathematical Literacy Processes in High School Students. International Journal of Trends in Mathematics Education Research, 2(3), 116. https://doi.org/10.33122/ijtmer.v2i 3.70

Heyden, K. Vander. (2016). A developmental perspective on spatial reasoning: Dissociating object transformation from viewer transformation ability. Cognitive Development, 38, 63-74. https://doi.org/10.1016/j.cogdev.20 16.01.004 
Indah Lestari, D., Haris EffendiHasibuan, M., \& Muhammad, D. (2020). The effect of the flipped classroom approach and selfefficacy on a guided inquiry on students' creative thinking skills. Jurnal Pendidikan Kimia, 12(2), 95-105.

https://doi.org/10.24114/jpkim.v12 i2.19435

Indrawati, F. A., \& Wardono. (2019). Pengaruh Self Efficacy Terhadap Kemampuan Literasi Matematika dan Pembentukan Kemampuan 4C. Prisma, Prosiding Seminar Nasional Matematika, 2, 247-267. file://C:/Users/sahabat/Downloads /29307-Article Text-66906-1-1020190228.pdf

Laurens, T., Batlolona, F. A., Batlolona, J. R., \& Leasa, M. (2017). How does realistic mathematics education (RME) improve students' mathematics cognitive achievement? Eurasia Journal of Mathematics, Science and Technology Education, 14(2), 569-578.

Lester, F. K., Garofalo, J., \& Kroll, D. L. (1989). Self-confidence, interest, beliefs, and metacognition: Key influences on problem-solving behavior. In Affect and mathematical problem solving (pp. 75-88). Springer.

OECD. (2013). PISA 2012 Results: What Students Know and Can DoStudent Performance in Mathematics, Reading and Science.

Ozgen, K. (2013). Self-efficacy beliefs in mathematical literacy and connections between mathematics and real world: The case of high school students. Journal of International Education Research (JIER), 9(4), 305-316.
Sumirattana, S. (2017). Using realistic mathematics education and the DAPIC problem-solving process to enhance secondary school students' mathematical literacy. Kasetsart Journal of Social Sciences, 38(3), 307-315. https://doi.org/10.1016/j.kjss.2016. 06.001

Tariq, V. N., Qualter, P., Roberts, S., Appleby, Y., \& Barnes, L. (2013). Mathematical literacy in undergraduates: role of gender, emotional intelligence and emotional self-efficacy.

International Journal of Mathematical Education in Science and Technology, 44(8), 1143-1159.

Wardono, Waluya, S. B., Mariani, S., \& Candra, S. D. (2016). Mathematics Literacy on Problem Based Learning with Indonesian Realistic Mathematics Education Approach Assisted E-Learning Edmodo. Journal of Physics: Conference Series, 693(1). https://doi.org/10.1088/17426596/693/1/012014

Yuanita, P. (2018). The effectiveness of Realistic Mathematics Education approach: The role of mathematical representation as mediator between mathematical belief and problem solving. PLoS $O N E$, 13(9). https://doi.org/10.1371/journal.pon e.0204847

Zaranis, N., Kalogiannakis, M., \& Papadakis, S. (2013). Using mobile devices for teaching realistic mathematics in kindergarten education. Creative Education, 4(07), 1. 